\title{
A Genetic Linkage Map of Phalaenopsis-based on AFLP Markers and the "Two-way Pseudo-testcross" Mapping Strategy
}

\author{
Shenping $\mathrm{Xu}^{1,2}$ and Feixiong $\mathrm{Liao}^{2 *}$ \\ ${ }^{1}$ Institute of Bioengineering, Zhengzhou Normal University, Zhengzhou 450044, China \\ ${ }^{2}$ College of Forestry and Landscape Archtecture, South China Agricultural University, Guangzhou 510642, China \\ *For correspondence: fxliao@scau.edu.cn
}

\begin{abstract}
Phalaenopsis are grown widely as cut-flowers and potted plants in the floriculture trade. Here, we report the genetic linkage maps for Phalaenopsis, which were developed by genotyping $88 \mathrm{~F}_{1}$ progenies from a cross between Phalaenopsis '462' (male) and Phalaenopsis '20' (female) with amplification fragment length polymorphisms (AFLP) in a 'two-way pseudotestcross" mapping strategy. For a total of 416 polymorphic loci showing Mendelian segregation were generated from 71 AFLP primer combinations. The data were analyzed using JoinMap 3.0 to construct the parent-specific linkage maps. The paternal map consisted of 15 linkage groups and 122 AFLP makers, covering $820.3 \mathrm{cM}$ with a mean distance of $6.7 \mathrm{cM}$ between adjacent markers. The maternal map consisted of 14 linkage groups with 175 loci, resulting in a total genetic distance of $878.3 \mathrm{cM}$ and an average genetic distance of $5.0 \mathrm{cM}$ between adjacent markers. Yet, as far as we know, this is the first study to construct the linkage map of Phalaenopsis. The two maps will serve as the frameworks for mapping of horticultural quantitative trait locis (QTLs) and furnish reference information for the application of future marker-assisted selection in Phalaenopsis breeding. (C) 2017 Friends Science Publishers
\end{abstract}

Keywords: Orchid; Molecular marker; Genetic analysis; Linkage

\section{Introduction}

The genus Phalaenopsis is one of the most commercially important orchids in the family Orchidaceae, grown as cut flowers and pot plants due to their long-lasting flowers and graceful appearance. Phalaenopsis industry is growing around the world in recent decade. Numerous varieties of Phalaenopsis have been developed and registered with the Royal Horticulture Society (RHS) each year. However, very limited research efforts have been devoted to understanding the genetic diversity (Been et al., 2002; Chang et al., 2009) or the genomic features of Phalaenopsis (Hsu et al., 2008) and genetic transformation (Liao et al., 2004; Sjahril et al., 2006). Although one Phalaenopsis genome was recently sequenced (Cai et al., 2015), the inheritance of important ornamental or horticultural traits, genetic relationships among important species, and the genomic organization of Phalaenopsis remained poorly understood, due to the complex genetic background and extensive hybridization in this genus.

Genetic linkage maps provide a powerful tool for comprehending the genetic basis of sophisticated traits in many plants (Lee, 1995). Particularly they are very useful for map-based cloning and the localization of important genes and assisting plant breeders in the selection of breeding parents and breeding lines. Genetic mapping in plants are often constructed utilizing segregating populations from crosses between inbred lines, but this strategy is not possible for many of those plants that have high heterozygosity and long life cycles, such as forest trees (Grattapaglia and Sederoff, 1994), fruit trees (Kenis and Keulemans, 2005), perennial flowers (Dunemann et al., 1999; Hibrand-Saint Oyant et al., 2008), etc. For these plants, the strategy of "two-way pseudo-testcross" has been adopted frequently. With this strategy, genetic linkage maps are constructed utilizing $\mathrm{F}_{1}$ offspring derived from the cross of two highly heterozygous individuals (Grattapaglia and Sederoff, 1994). For example, the method has been utilized successfully to construct linkage maps in agronomic crops such as peanut (Hong et al., 2008) and sweetpotato (Kriegner et al., 2003), ornamental plants such as wintersweet (Chen and Chen, 2010) and dendrobium (Xue et al., 2010), and tree species such as pistacia (Turkeli and Kafkas, 2013) and Eucommia ulmoides (Wang et al., 2014).

Many species in Phalaenopsis are diploids with a chromosome number of $2 n=2 x=38$, although some species have different chromosome numbers as revealed by cytological studies (Christenson, 2001; Kao et al., 2001). Hybridization occurs easily in Phalaenopsis, not only between the species but also with members of related genera. Because of frequent hybridizations, most Phalaenopsis varieties are highly heterozygous. In addition, 
developing inbred lines in Phalaenopsis has been rather difficult. Considering these factors, the "two-way pseudotestcross" strategy seemed to be an effective and convenient way for constructing genetic linkage maps in Phalaenopsis. The objective of this study was to apply the AFLP marker system to Phalaenopsis, to develop maternal and paternal pure-coupling phase AFLP markers, and construct linkage maps using the mapping strategy of "two-way pseudotestcross". We expect that these markers and the linkage maps would be valuable for identifying markers associated with important traits of interest and improving the breeding efficiency in this important orchid.

\section{Materials and Methods}

\section{Plant Materials}

The mapping population used was a hybrid population developed from two cultivars, Phalaenopsis '20' and '462'. Phalaenopsis ' 20 ' was characterized by creamy yellow flowers with small mahogany spots, medium-sized leaves, and slight fragrance, and it was used as the female parent of the population. The male parent was Phalaenopsis '462', whose flowers were creamy white overlaid with large waxy magenta spots. This variety had large leaves and no fragrance. Hybrid seedlings were produced by germinating the seeds on an aseptic MS medium with the addition of sucrose at $30 \mathrm{~g} \cdot \mathrm{L}^{-1}$ and agar at $6 \mathrm{~g} \cdot \mathrm{L}^{-1}$. Seedlings were transplanted individually to plastic containers filled with sphagnum moss and then grown in an environmentcontrolled greenhouse for 6 months. After that 88 individual plants were randomly picked out of 450 progenies to construct the mapping population.

\section{DNA Extraction}

Genomic DNA of Phalaenopsis was extracted from the fresh leaves using the cetyltrimethy lammonium bromide (CTAB) methods described by Murray and Thompson (1980) with minor modifications. A $0.5 \mathrm{~g}$ fresh leaf tissue was pulverized using liquid nitrogen, and then the powder was gently dispersed in an extraction buffer based on Murray and Thompson (1980), and then incubated at $65^{\circ} \mathrm{C}$ for $20 \mathrm{~min}$. During the incubation, samples were shaken gently. The extract was mixed with an equal volume of octanol:chloroform (1:24), the aqueous phase was transferred to a clean centrifuge tube after centrifugation $(13,000 \times \mathrm{g}, 10 \mathrm{~min})$. DNA was precipitated from the supernatant by adding absolute alcohol and centrifugation. The pellet of DNA was washed with $75 \%$ alcohol and finally dissolved in $100 \mu \mathrm{L}$ of TE buffer and incubated at $37^{\circ} \mathrm{C}$ for $1 \mathrm{~h}$. The quantity and quality of the DNA were appraised by electrophoresis on 1\% Agarose-gels with a standard weight Lambda DNA (Sigma).

\section{AFLP Protocol, Primer Screening and Marker Scoring}

AFLPs analyses were performed using the restriction enzyme combination PstI and MseI according to the method of Vos et al. (1995). For each progeny, $100 \mathrm{ng}$ of genomic DNA was digested in a $12.5 \mu \mathrm{L}$ reaction with 2.5 units of PstI and MseI (Sigma) at $37^{\circ} \mathrm{C}$ for $6 \mathrm{~h}$. The reaction contained $1.25 \mu \mathrm{L}$ of $10 \times \mathrm{NE}$ buffer 4 and $0.15 \mu \mathrm{L}$ of $100 \times$ BSA. After digestion, $1.5 \mu \mathrm{L}$ of $10 \times \mathrm{T}_{4}$ DNA ligase buffer, 1.25 units of T4 DNA ligase and 1.25 units of PstI and MseI adapters were added to the reaction and the reaction was incubated at $37^{\circ} \mathrm{C}$ for another $3 \mathrm{~h}$ to ligate the adapters to the restricted DNA fragments.

After enzymatic restriction and adaptor ligation, an aliquot of $2.5 \mu \mathrm{L}$ of the reaction was diluted 60 times with TE Buffer, and the diluted reaction was used for preamplification. The PCR reaction for the pre-amplification contained, $35 \mathrm{ng}$ of PstI and MseI primers, $0.5 \mu \mathrm{L}$ of dNTP mixture $(10 \mathrm{mM}), 0.5 \mu \mathrm{L}$ of $\mathrm{MgCl}_{2}$ stock solution $(25 \mathrm{mM})$, $0.9 \mu \mathrm{L}$ of $10 \times$ PCR buffer (non- $\mathrm{Mg}^{2+}$ ), 5 units of Taq DNA Polymerase in a total volume of $25 \mu \mathrm{L}$. The preamplification PCR was performed on PCR instrument (Eppendorf, Hamburg, Germany) with the cycling program of described by Vos et al. (1995).

All pre-amplification reactions were diluted 60 times with purified water and then $1 \mu \mathrm{L}$ of this dilution was used in a $20 \mu \mathrm{L}$ volume mixture for selective amplification. Each selective amplification reaction contained $5 \mathrm{ng}$ of the PstI primer, $30 \mathrm{ng}$ of the $\mathrm{Mse}$ primer, $0.4 \mu \mathrm{L}$ of dNTP mixture $(10 \mathrm{mM}), 2 \mu \mathrm{L}$ of the $10 \times$ PCR buffer (non- $\mathrm{Mg}^{2+}$ ), $\quad 1.6 \mu \mathrm{L}$ of $\mathrm{MgCl}_{2}$ solution $(25 \mathrm{mM})$, and 0.4 units of Taq DNA Polymerase. Then the sample were amplified by PCR system and separated by $6 \%$ denatured polyacrylamide gels and DNA bands were visualized by silver staining. Primer combinations with three selective nucleotides $(M s e \mathrm{I}+3 / P s t \mathrm{I}+3)$ were screened to identify those that could amplify clear and unambiguous polymorphic fragments in both Phalaenopsis '462' and '20'.

AFLP marker fragments on the silver stained gels were manually scored for their absence (0) or presence (1). The distinguished clearly fragments were scored and recorded. There were a few ambiguous fragments in a few individuals. These fragments were resolved by assigning a blank score (-) for map construction. All AFLP markers were identified by primer combinations utilizing the primer notation (Vos et al., 1995). The bands of polymorphic were named serially in the descending order of molecular weight. Recorded markers would be split into three groups according to the absence or presence within each parent. AFLP fragments that were present exclusively in the male parent were given the prefix $\mathrm{M}$, while those present only in the female parent were given the prefix F, and those fragments appearing in both parents were given the prefix MF.

\section{Data Analysis and Genetic Linkage Map Construction}

In the pseudo-testcross configuration, Mendelian segregation was tested for all markers at a 5\% 
signification level by performing a chi square $\left(\chi^{2}\right)$ goodness-of-fit test to testcross $(1: 1)$ and intercross $(3: 1)$ marker ratios. The segregation of markers heterozygous in one parent was tested against a $1: 1$ ratio using a $\chi^{2}$ test, while those heterozygous in two parents were tested against a ratio of $3: 1$. Those markers that did not segregate in the $1: 1$ or $3: 1$ ratio were treated as distorted ones.

AFLP markers were categorized into three types: (1) those manifesting segregation only in the male parent (Phalaenopsis '462'), (2) those manifesting segregation only in the female parent (Phalaenopsis '20'), and (3) those manifesting segregation in two parents. AFLP markers of the three types were used to construct the genetic linkage map for Phalaenopsis, and types 1, 3 for Phalaenopsis '462', types 2 and 3 for Phalaenopsis '20', following the methods of Grattapaglia and Sederoff (1994). Linkage maps were generated independently for each parent using JoinMap 3.0 (Van Ooijen and Voorrips, 2001) based on LOD scores (minimum LOD score of 3.0). The detection of linkage among AFLP markers were based on pair-wise recombination estimates with a threshold recombination fraction $<0.45$ and a threshold LOD score $>3.0$. Genetic distances were converted from recombination fractions into centiMorgans (cM) according to Kosambi (1943). Final linkage mapping was drawn using the software MapChart 2.1 (Voorrips, 2002).

\section{Results}

\section{Polymorphism of AFLP Markers}

Out of the 570 AFLP primer combinations tested, 71 showed polymorphisms that were highly reproducible and then used to evaluate the $88 \mathrm{~F}_{1}$ progenies. Through the analysis of AFLP, the fragments size ranged from 50 to $1500 \mathrm{bp}$. These 71 primer combinations produced 865 amplification products, of which 416 showed polymorphic characteristics (Table 1). The number of polymorphic AFLP markers generated by each primer combination varied from 1 to 13 , with an average of 5.86 polymorphic fragments per primer combination. Of these AFLP markers, 149 bands were amplified in the male parent and 226 in the female parent, and these markers were expected to segregate in a $1: 1$ ratio $(\mathrm{P}<$ $0.05)$. Forty-one markers were detected in two parents and they were predicted to segregate in a $3: 1$ ratio $(\mathrm{P}<$ $0.05)$ in the $F_{1}$ population.

Though the analysis of chi square, the 314 (75.48\%) polymorphic markers showed a compatible fit to the anticipated segregation ratio of $1: 1$ or $3: 1$, and $102(24.52 \%)$ polymorphic markers gave a significant segregation distortion from the anticipated ratio of $1: 1$ or $3: 1(P=0.05)$. Out of 314 polymorphic markers, 175 (55.73\%) were segregating in female, 109 (34.71\%) through male and 30 $(9.56 \%)$ through co-parental.

\section{Map Construction}

When the 416 AFLP markers were suffered to two-point linkage analysis using JoinMap 3.0, 292 markers were found suitable for linkage map construction. The remaining 124 markers (49\% in female parent, $36 \%$ in male parent, and $15 \%$ in two parents) were not included because these markers did not accord with the linkage grouping or ordering thresholds (LOD score $\geq 3.0$ ) of the pseudotestcross mapping strategy in JoinMap 3.0. Two independent maps were constructed for each Phalaenopsis parental cultivar.

The genetic linkage map of Phalaenopsis '462' consisted of 122 markers (104 for the male parent, 18 for co-parents) in 15 linkage groups, and had a total genetic distance of $820.28 \mathrm{cM}$ (Fig. 1). The length of the linkage groups varied from $3.67 \mathrm{cM}$ to $168.96 \mathrm{cM}$, with an average of $6.72 \mathrm{cM}$ between adjacent markers. The largest gap between two markers $(37.8 \mathrm{cM})$ was found on Linkage Group 9. The average number of markers per linkage group was 8.13, ranging from 2 to 57 for each linkage group.

For Phalaenopsis '20', a total of 175 (165 for female parent, 10 for co-parents) markers were placed into 14 linkage groups, defining a total genetic distance of 878.29 $\mathrm{cM}$ (Fig. 2). The length of the linkage groups varied from $6.2 \mathrm{cM}$ to $181.61 \mathrm{cM}$. The average distance between adjacent markers was $5.02 \mathrm{cM}$. The largest gap between two markers was found in Linkage Group 5. The number of markers for each linkage group varied from 2 to 107, with an average of 12.5 markers per linkage group.

\section{Homologous Linkage Groups}

AFLP loci that were heterozygous in both parents could help bridge homologous linkage groups of the coparental map. In this study, 23 markers out of 41 shared by both parents were mapped on the parental maps, with 18 markers assigned on the male Phalaenopsis '462' map and 10 on the female Phalaenopsis '20' map. The homologous group nodes of two parental maps were formed in the five linkage groups. Markers MFP1-M17450 and MFP13-M38-500 were detected in the linkage groups FLG-1 and MLG-1, markers MFP3-M19-600 in the linkage groups FLG-14 and MLG-1, and markers MFP11-M11-750 and MFP2-M10-500 in the linkage groups FLG-9 and MLG-3 (Fig. 3). Therefore, homologous relationships could exist in the linkage groups of bi-parentals.

\section{Discussion}

Compared with other markers, AFLP is a dominant PCRbased marker, requiring relatively little template DNA and little prior knowledge of the target template DNA sequence, and reveals high levels of polymorphism in many species. 
Table 1: The number of polymorphic fragments and mapped fragments generated by each of 71 Pst $+3 / M s e I+3$ primer combinations in the development of the genetic linkage maps of Phalaenopsis '462' $\times$ Phalaenopsis ' 20 '

\begin{tabular}{|c|c|c|c|c|c|c|c|}
\hline Primer combinations & Primer code & $\begin{array}{l}\text { Number of } \\
\text { polymorphic } \\
\text { fragments }\end{array}$ & $\begin{array}{l}\text { Number of } \\
\text { mapped } \\
\text { fragments }\end{array}$ & Primer combinations & $\begin{array}{l}\text { Number of } \\
\text { polymorphic } \\
\text { fragments }\end{array}$ & $\begin{array}{l}\text { Number of } \\
\text { mapped } \\
\text { fragments }\end{array}$ & $\begin{array}{l}\text { Mapped } \\
\text { markers }\end{array}$ \\
\hline 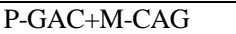 & P1-M3 & 6 & 5 & P-GCT+M-ACT & P5-M11 & 8 & 6 \\
\hline P-GAC+M-CTA & P1-M6 & 6 & 4 & P-GCT+M-ACA & P5-M27 & 3 & 2 \\
\hline P-GAC+M-AAC & P1-M8 & 5 & 3 & P-GCT+M-GAC & P5-M32 & 7 & 5 \\
\hline P-GAC+M-AAG & P1-M9 & 4 & 2 & P-GCT+M-GCG & P5-M38 & 13 & 9 \\
\hline P-GAC+M-ACC & P1-M10 & 5 & 4 & P-GCG+M-CAG & P6-M3 & 4 & 4 \\
\hline P-GAC+M-ACT & P1-M11 & 5 & 3 & P-GCG+M-AAC & P6-M8 & 5 & 2 \\
\hline P-GAC+M-ATC & P1-M16 & 5 & 4 & P-GCG+M-AAG & P6-M9 & 6 & 3 \\
\hline P-GAC+M-ATG & P1-M17 & 7 & 4 & P-GCG+M-ACT & P6-M11 & 9 & 6 \\
\hline P-GAC+M-CCG & P1-M18 & 4 & 1 & P-GCG+M-AGC & P6-M12 & 9 & 6 \\
\hline P-GAC+M-CCT & P1-M19 & 4 & 4 & P-GCG+M-ATC & P6-M16 & 7 & 6 \\
\hline P-GAC+M-CTG & P1-M21 & 3 & 3 & P-GCG+M-CTC & P6-M20 & 1 & 1 \\
\hline P-GAC+M-CGA & P1-M22 & 8 & 7 & P-GCG+M-GAG & P6-M33 & 4 & 4 \\
\hline P-GAC+M-ACA & P1-M27 & 6 & 4 & P-GCG+M-GTA & P6-M36 & 4 & 2 \\
\hline P-GAC+M-ATT & P1-M30 & 4 & 3 & P-GCG+M-GTT & P6-M37 & 6 & 5 \\
\hline P-GAG+M-CAG & P2-M3 & 7 & 6 & $\mathrm{P}-\mathrm{GGA}+\mathrm{M}-\mathrm{ACC}$ & P10-M10 & 4 & 4 \\
\hline P-GAG+M-AAG & P2-M9 & 4 & 2 & P-GGA+M-ACT & P10-M11 & 9 & 9 \\
\hline P-GAG+M-ACC & P2-M10 & 8 & 5 & $\mathrm{P}-\mathrm{GGC}+\mathrm{M}-\mathrm{AAC}$ & P11-M8 & 12 & 7 \\
\hline P-GAG+M-ACT & P2-M11 & 4 & 4 & P-GGC+M-AAG & P11-M9 & 13 & 11 \\
\hline P-GAG+M-AGT & P2-M14 & 8 & 4 & P-GGC+M-ACC & P11-M10 & 3 & 3 \\
\hline P-GAG+M-ATC & P2-M16 & 1 & 1 & P-GGC+M-ACT & P11-M11 & 12 & 10 \\
\hline P-GAG+M-ATG & P2-M17 & 7 & 5 & P-GGC+M-AGG & P11-M13 & 10 & 7 \\
\hline P-GAG+M-CCG & P2-M18 & 6 & 5 & P-GGC+M-ATC & P11-M16 & 2 & 2 \\
\hline P-GAG+M-CTG & P2-M21 & 12 & 4 & P-GGC+M-GAC & P11-M32 & 9 & 6 \\
\hline P-GAG+M-CGA & P2-M22 & 11 & 6 & P-GGC+M-GAG & P11-M33 & 6 & 6 \\
\hline P-GAG+M-CGG & P2-M24 & 9 & 6 & P-GGC+M-GCG & P11-M38 & 2 & 1 \\
\hline P-GAG+M-GAG & P2-M33 & 7 & 3 & P-GGT+M-AAG & P12-M9 & 2 & 2 \\
\hline P-GAG+M-GAT & P2-M34 & 6 & 4 & P-GGT+M-ACA & P12-M27 & 5 & 4 \\
\hline P-GAG+M-GTA & P2-M36 & 3 & 2 & P-GGT+M-ACG & P12-M28 & 4 & 3 \\
\hline P-GAG+M-GCG & P2-M38 & 11 & 8 & P-GGT+M-GAC & P12-M32 & 5 & 4 \\
\hline P-GAT+M-CAG & P3-M3 & 5 & 3 & P-GGT+M-GTT & P12-M37 & 10 & 9 \\
\hline P-GAT+M-CCA & P3-M5 & 4 & 2 & P-GGT+M-GCG & P12-M38 & 5 & 5 \\
\hline P-GAT+M-CCG & P3-M18 & 1 & 0 & P-GAA+M-CAG & P13-M3 & 4 & 3 \\
\hline P-GAT+M-CCT & P3-M19 & 3 & 2 & P-GAA+M-CAT & P13-M4 & 3 & 2 \\
\hline P-GAT+M-CTC & P3-M20 & 6 & 0 & P-GAA+M-CTG & P13-M21 & 2 & 1 \\
\hline P-GAT+M-CTG & P3-M21 & 5 & 2 & P-GAA+M-GCG & P13-M38 & 6 & 5 \\
\hline P-GCT+M-ACC & P5-M10 & 4 & 2 & - & - & - & - \\
\hline
\end{tabular}

This molecular marker system has been used in the studies of genetic diversity and gametophyte selection of Phalaenopsis (Hsu et al., 2008; Chang et al., 2009, 2010; Gawenda et al., 2012). The AFLP technique has been widely used for linkage mapping in many plants including sweetpotato (Kriegner et al., 2003), velvetbean (CapoChichi et al., 2004), apple (Kenis and Keulemans, 2005), wintersweet (Chen and Chen, 2010), crape myrtle (He et al., 2014), and Eucommia ulmoides (Wang et al., 2014). A high level of DNA polymorphism detected by AFLP technique in Phalaenopsis allowed us to construct its genetic linkage map using $\mathrm{F}_{1}$ progenies.

AFLP markers were sensitive to segregation distortion and highly distorted markers had been discovered in many species (Behrend et al., 2013; Chen et al., 2013; Han et al., 2002), which was supposed to be one of the forces for biological evolution (Konishi et al., 1990). The segregation distortion was often much higher in inter-specific populations than in intra-specific populations (Myburg et al., 2003) and caused from biological reasons such as gametes selection, faulty chromosome pairing and so on (Zhang et al., 2010). There were an average $24.42 \%$ of the distorted segregation in our study of Phalaenopsis, which was similar to $22.61 \%$ in crape myrtle (He et al., 2014), $24.8 \%$ in lily (Abe et al., 2002) and $23.5 \%$ in rhododendron (Dunemann et al., 1999), and less than $34.8 \%$ in wintersweet (Chen and Chen, 2010). Highly distorted segregation markers used to construct genetic maps did not affected marker order and map length (Hackett and Broadfoot, 2003), so some genetic maps were constructed without removing the segregation markers (Ky et al., 2000; Han et al., 2002; Yan et al., 2005; Behrend et al., 2013). Here, maybe the biological cause was the main reason. Most of Phalaenopsis are heterozygous at the gene, including both the parents. Thus, further researches with intraspecific crosses, larger progenies and more molecular markers would be helpful to study the segregation distortion in Phalaenopsis. Considering the addition of distorted markers could increase the identification of regions of interest in further study of Phalaenopsis, 
A Genetic Linkage Map of Phalaenopsis / Int. J. Agric. Biol., Vol. 19, No. 3, 2017

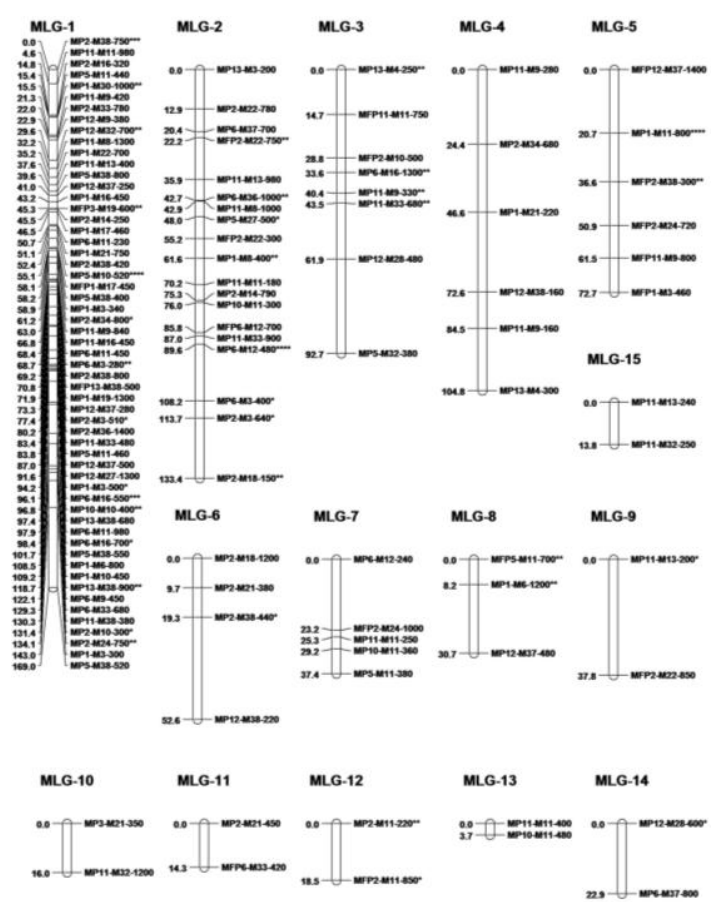

Fig. 1: Genetic linkage map of Phalaenopsis ' 462 ' based on the segregation of AFLP markers in a population of 88 $F_{1}$ progenies. For each linkage group, the names of AFLP markers are shown on the right side and the marker intervals in Kosambi centimorgans (cM) and their map position shown on the left side. For details of AFLP marker nomenclature see Table 1. Asterisks indicate distorted segregation of markers $\left(\chi^{2}\right.$ test $) * p=0.05, * * p=$ $0.01,{ }^{* * *} \mathrm{p}=0.005,{ }^{* * * *} \mathrm{p}=0.001,{ }^{* * * * *} \mathrm{p}=0.0005$

the distorted markers were not discarded and marked with asterisks on the construction of genetic map in this study.

Nineteen link groups were anticipated to be mapped corresponding to the haploid chromosomes number for genus Phalaenopsis $(2 \mathrm{n}=38)$. However, only 15 linkage groups were obtained in the male map (Fig. 1) and 14 in the female map (Fig. 2) in this study. Similar situation had been reported in other plant species (Mignouna et al., 2002; Chen and Chen, 2010; Xue et al., 2010; Zheng et al., 2013). In this paper, a low number of markers and small population were related to small linkage groups and unlinked markers. With additional markers and larger population, a much more comprehensive genetic map of Phalaenopsis would be constructed.

The wide marker space of 20 or even $50 \mathrm{cM}$ may be optimal for QTL mapping scanning (Darvasi et al., 1993). In this study, AFLP markers with the average recombination distance were $6.72 \mathrm{cM}$ and $5.02 \mathrm{cM}$, respectively for parental linkage maps that provided a favorable situation for QTL scanning.

The clustering of many markers loci to one or two linkage groups intensively seems a common phenomenon in

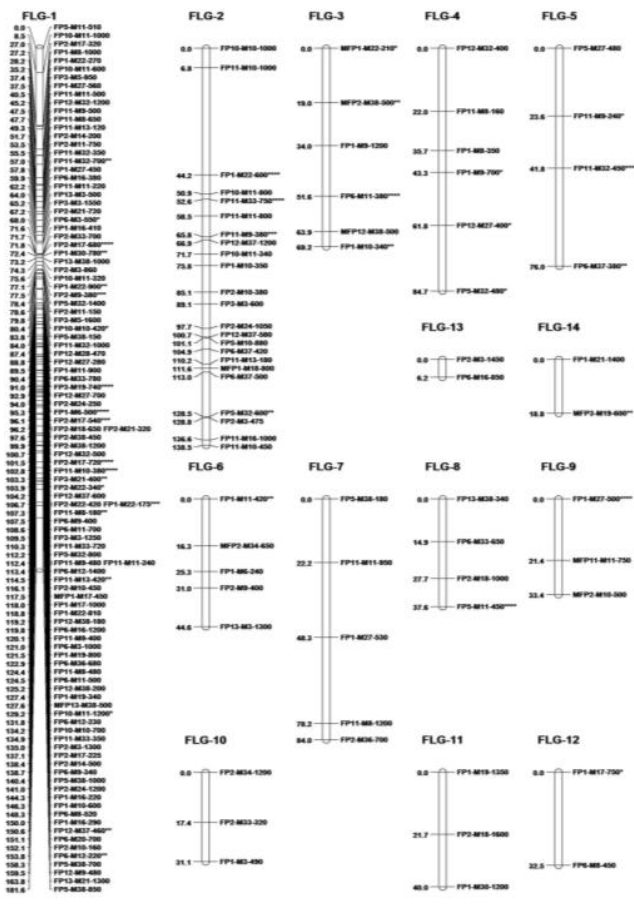

Fig. 2: Genetic linkage map of Phalaenopsis '20' based on the segregation of AFLP markers in a population of $88 \mathrm{~F}_{1}$ progenies. For each linkage group, the names of markers are shown on the right side and the marker intervals shown in Kosambi centimorgans (cM) their map position (cM) on the left side. For details of AFLP marker nomenclature see Table 1. Asterisks indicate distorted segregation of markers $\left(\chi^{2}\right.$ test $) * \mathrm{p}=0.05, * * \mathrm{p}=0.01, * * * \mathrm{p}=0.005, * * * * \mathrm{p}=$ $0.001, * * * * * \mathrm{p}=0.0005$

AFLP genetic linkage maps (Ouédraogo et al., 2002; Strommer et al., 2002). This occurred in FLG-1 and MLG-1 of Phalaenopsis map. One of the reasons for this intensive clustering phenomenon may be the higher sensitivity of the AFLP technique because the degraded recombination rate near centromere or telomere, nonequal of restriction enzyme sites and high repeat factor could cause these intensive clustering markers (Strommer et al., 2002). AFLP markers from EcoRI/MseI restriction enzymes were found to concentrate often in the vicinity of the centromere of chromosome due to centromeric suppression of recombination (Haanstra et al., 1999; Bonnema et al., 2002), while contrarily the polymorphic markers from PstI/MseI restriction enzymes were distributed more equally than that marker from $E c o R \mathrm{I} / \mathrm{Mse}$ I restriction enzymes in the genome (Pradhan et al., 2003). However, PstI/MseI were used as restriction enzymes in this study. High density clustering of markers still appeared in the linkage groups in FLG-1 and MLG-1. It has been argued that high density clustering may be the results of the recombination or too small mapping population (De la Rosa et al., 2003). 


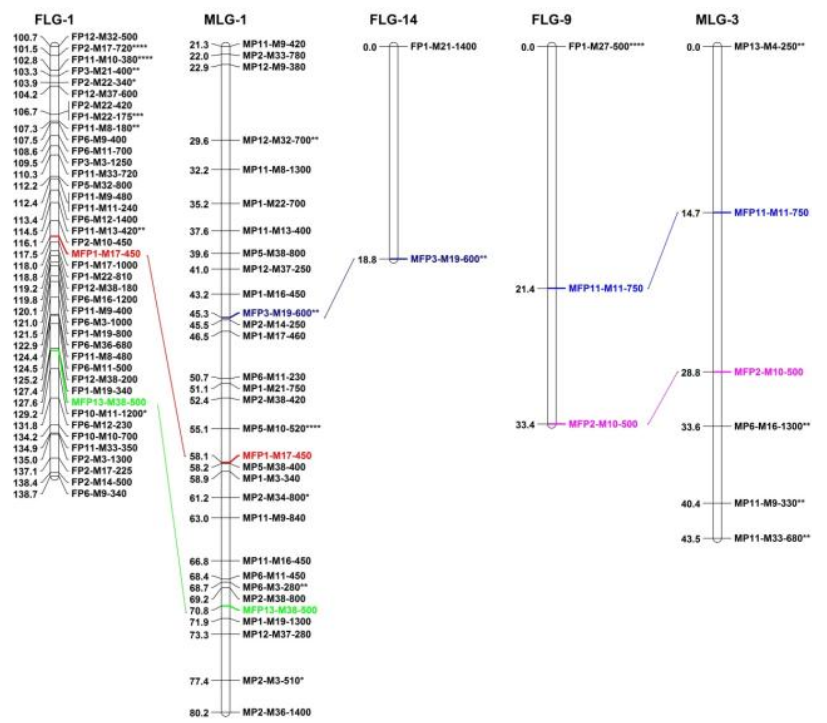

Fig. 3: Homologous linkage groups of both maps are presented side by side. For each linkage group, the names of markers are shown at the left and the marker intervals shown in Kosambi centimorgans (cM) their map position $(\mathrm{cM})$ at the right. For details of AFLP marker nomenclature see Table 1. Asterisks indicate distorted segregation of markers $\left(\chi^{2}\right.$ test $) * \mathrm{p}=0.05, * * \mathrm{p}=0.01,{ }^{* * *} \mathrm{p}=0.005$, $* * * * \mathrm{p}=0.001, * * * * * \mathrm{p}=0.0005$

\section{Conclusion}

A preliminary genetic linkage map was constructed for Phalaenopsis by AFLP markers, a species that was relatively lacking the genetic information. To our knowledge, this was the first linkage map for Phalaenopsis, which may serve as a tool in QTL analysis, molecular marker assisted selection, and map-based cloning in further study, especially the linkage between molecular markers and valuable genes was the premise for cloning gene such as fragrance, growth habit and flower color, or other single gene traits on the maps. However, this map was not saturated, more additional markers and larger population needed to be used to construct a much more comprehensive genetic map of Phalaenopsis.

\section{Acknowledgements}

This work was supported by the Talent introduction fund of South China Agricultural University and by Science \& Technology planning Projects (Grant No. 152107000071; 162102110073) of Henan Province. Much thanks to Mr. Zhang Mengjin for his help in cultivation and management techniques of Phalaenopsis. We appreciated Professor JianJun Chen of Mid-Florida Research and Education Center, Professor Zhanao Deng of Gulf-coast Research and Education Center, UF/IFAS for critically reading this manuscript.

\section{References}

Abe, H., M. Nakano, A. Nakatsuka, M. Nakayama, M. Koshioka and M. Yamagishi, 2002. Genetic analysis of floral anthocyanin pigmentation traits in Asiatic hybrid lily using molecular linkage maps. Theor. Appl. Genet., 8: 1175-1182

Been, C., A. Na, J. Kim and H.Y. Kim, 2002. Random amplified polymorphic DNA (RAPD) for genetic analysis of Phalaenopsis species. Hortic. Environ. Biotechnol., 4: 387-391

Behrend, A., T. Borchert, M. Spiller and A. Hohe, 2013. AFLP-based genetic mapping of the "bud-flowering" trait in heather (Calluna vulgaris). BMC Genet., 1: 1-11

Bonnema, G., P.V.D. Berg and P. Lindhout, 2002. AFLPs mark different genomic regions compared with RFLPs: a case study in tomato. Genome, 2: 217-221

Cai, J., X. Liu, K. Vanneste, S. Proost, W.C. Tsai, K.W. Liu, L.J. Chen, Y. He, Q. Xu, C. Bian, Z. Zheng, F. Sun, W. Liu, Y.Y. Hsiao, Z.J. Pan, C.C. Hsu, Y.P. Yang, Y.C. Hsu, Y.C. Chuang, A. Dievart, J.F. Dufayard, X. Xu, J.Y. Wang, J. Wang, X.J. Xiao, X.M. Zhao, R. Du, G.Q. Zhang, M. Wang, Y.Y. Su, G.C. Xie, G.H. Liu, L.Q. Li, L.Q. Huang, Y.B. Luo, H.H. Chen, Y. Van de Peer and Z.J. Liu, 2015. The genome sequence of the orchid Phalaenopsis equestris. Nat. Genet., 1: $65-72$

Capo-Chichi, L., C.M. Morton and D.B. Weaver, 2004. An intraspecific genetic map of velvetbean (Mucuna sp.) based on AFLP markers. Theor. Appl. Genet., 5: 814-821

Chang, Y., L.A. Blischak, R.E. Veilleux and M.J. Iqbal, 2010. Effect of temperature on gametophytic selection in a Phalaenopsis $\mathrm{F}_{1}$ population. Euphytica, 2: 251-261

Chang, Y., R.E. Veilleux and M.J. Iqbal, 2009. Analysis of genetic variability among Phalaenopsis species and hybrids using amplified fragment length polymorphism. J. Amer. Soc. Hortic. Sci., 1: 58-66

Chen, D. and L. Chen, 2010. The first intraspecific genetic linkage maps of wintersweet [Chimonanthus praecox (L.) Link] based on AFLP and ISSR markers. Sci. Hortic., 1: 88-94

Chen, M., F. Feng, X. Sui and S. Han, 2013. Genetic linkage maps of Pinus koraiensis Sieb. et Zucc. based on AFLP markers. Afr. J. Biotechnol., 35: 5659-5664

Christenson, E.A., 2001. Phalaenopsis. a Monograph, pp: 68-70. Timber Press, Oregon

Darvasi, A., A. Weinreb, V. Minke, J.I. Weller and M. Soller, 1993. Detecting marker-QTL linkage and estimating QTL gene effect and map location using a saturated genetic map. Genetics, 3: 943-951

De la Rosa, R., A. Angiolillo, C. Guerrero, M. Pellegrini, L. Rallo, G. Besnard, A. Berville, A. Martin and L. Baldoni, 2003. A first linkage map of olive (Olea europaea L.) cultivars using RAPD, AFLP, RFLP and SSR markers. Theor. Appl. Genet., 7: 1273-1282

Dunemann, F., R. Kahnau and I. Stange, 1999. Analysis of complex leaf and flower characters in Rhododendron using a molecular linkage map. Theor. Appl. Genet., 6-7: 1146-1155

Gawenda, I., A. Schröder-Lorenz and T. Debener, 2012. Markers for ornamental traits in Phalaenopsis orchids. population structure, linkage disequilibrium and association mapping. Mol. Breed., 1: 305-316

Grattapaglia, D. and R. Sederoff, 1994. Genetic linkage maps of Eucalyptus grandis and Eucalyptus urophylla using a pseudo-testcross: mapping strategy and RAPD markers. Genetics, 4: 1121-1137

Haanstra, J., C. Wye, H. Verbakel, F. Meijer-Dekens, P. Van den Berg, P. Odinot, A.W. Van Heusden, S. Tanksley, P. Lindhout and J. Peleman, 1999. An integrated high-density RFLP-AFLP map of tomato based on two Lycopersicon esculentum $\times$ L. pennellii $\mathrm{F}_{2}$ populations. Theor. Appl. Genet., 1-2: 254-271

Hackett, C.A. and L.B. Broadfoot, 2003. Effects of genotyping errors, missing values and segregation distortion in molecular marker data on the construction of linkage maps. Heredity, 1: 33-38

Han, T., H. van Eck, M. de Jeu and E. Jacobsen, 2002. The construction of a linkage map of Alstroemeria aurea by AFLP markers. Euphytica, 2: $153-164$ 
He, D., Y. Liu, M. Cai, H. Pan and Q. Zhang, 2014. The first genetic linkage map of crape myrtle (Lagerstroemia) based on amplification fragment length polymorphisms and simple sequence repeats markers. Plant. Breed., 1: 138-144

Hibrand-Saint Oyant, L., L. Crespel, S. Rajapakse, L. Zhang and F. Foucher, 2008. Genetic linkage maps of rose constructed with new microsatellite markers and locating QTL controlling flowering traits. Tree. Genet. Genomes, 1: 11-23

Hong, Y., X. Liang, X. Chen, H. Liu, G. Zhou, S. Li and S. Wen, 2008 Construction of Genetic Linkage Map Based on SSR Markers in Peanut (Arachis hypogaea L.). Agric. Sci. China., 8: 915-921

Hsu, T., W. Tsai, D. Wang, S. Lin, Y. Hsiao, W. Chen and H. Chen, 2008. Differential gene expression analysis by cDNA-AFLP between flower buds of Phalaenopsis Hsiang Fei cv. H. F. and its somaclonal variant. Plant Sci., 3: 415-422

Kao, Y., S. Chang, T. Lin, C. Hsieh, Y. Chen, W. Chen and C. Chen, 2001. Differential accumulation of heterochromatin as a cause for karyotype variation in Phalaenopsis orchids. Ann. Bot., 3: 387-395

Kenis, K. and J. Keulemans, 2005. Genetic linkage maps of two apple cultivars based on AFLP and microsatellite markers. Mol. Breed., 2: 205-219

Konishi, T., K. Abe, S. Matsuura and Y. Yano, 1990. Distorted segregation of the esterase isozyme genotypes in barley (Hordeum vulgare L.). Jpn. J. Genet., 6: 411-416

Kosambi, D.D., 1943. The estimation of map distances from recombination values. Ann. Hum. Genet., 1: 172-175

Kriegner, A., J.C. Cervantes, K. Burg, R.O. Mwanga and D. Zhang, 2003. A genetic linkage map of sweetpotato [Ipomoea batatas (L.) Lam.] based on AFLP markers. Mol. Breed., 3: 169-185

Ky, C., P. Barre, M. Lorieux, P. Trouslot, S. Akaffou, J. Louarn, A. Charrier, S. Hamon and M. Noirot, 2000. Interspecific genetic linkage map, segregation distortion and genetic conversion in coffee (Coffea sp.) Theor. Appl. Genet., 4: 669-676

Lee, M., 1995. DNA markers and plant breeding programs. Adv. Agron., 55: 265-344

Liao, L., I. Pan, Y. Chan, Y. Hsu, W. Chen and M. Chan, 2004. Transgene silencing in Phalaenopsis expressing the coat protein of Cymbidium Mosaic Virus is a manifestation of RNA-mediated resistance. Mol. Breed., 3: 229-242

Mignouna, H., R. Mank, T. Ellis, N. Van Den Bosch, R. Asiedu, S. Ng and J. Peleman, 2002. A genetic linkage map of Guinea yam (Dioscorea rotundata Poir.) based on AFLP markers. Theor. Appl. Genet., 5: 716-725

Murray, M.G. and W.F. Thompson, 1980. Rapid isolation of high molecular weight plant DNA. Nucleic. Acids Res., 19: 4321-4326

Myburg, A.A., A.R. Griffin, R.R. Sederoff and R.W. Whetten, 2003. Comparative genetic linkage maps of Eucalyptus grandis, Eucalyptus globulus and their F1 hybrid based on a double pseudobackcross mapping approach. Theor. Appl. Genet., 6: 1028-1042
Ouédraogo, J.T., B.S. Gowda, M. Jean, T.J. Close, J.D. Ehlers, A.E. Hall, A.G. Gillaspie, P.A. Roberts, A.M. Ismail and G. Bruening, 2002. An improved genetic linkage map for cowpea (Vigna unguiculata L.) combining AFLP, RFLP, RAPD, biochemical markers, and biological resistance traits. Genome, 1: 175-188

Pradhan, A., V. Gupta, A. Mukhopadhyay, N. Arumugam, Y. Sodhi and D. Pental, 2003. A high-density linkage map in Brassica juncea (Indian mustard) using AFLP and RFLP markers. Theor. Appl. Genet., 4: $607-614$

Sjahril, R., D.P. Chin, R.S. Khan, S. Yamamura, I. Nakamura, Y. Amemiya and M. Mii, 2006. Transgenic Phalaenopsis plants with resistance to Erwinia carotovora produced by introducing wasabi defensin gene using Agrobacterium method. Plant. Biotechnol., 2: 191-194

Strommer, J., J. Peters, J. Zethof, P. De Keukeleire and T. Gerats, 2002. AFLP maps of Petunia hybrida. building maps when markers cluster. Theor. Appl. Genet., 6-7: 1000-1009

Turkeli, Y. and S. Kafkas, 2013. First genetic linkage map in pistachio constructed using an interspecific cross between Pistacia vera $\mathrm{L}$. and monoecious Pistacia atlantica Desf. Sci. Hortic., 151: 30-37

Van Ooijen, J.W. and R.E. Voorrips, 2001. JoinMap 3.0 software. Plant Research International, Wageningen, the Netherlands

Voorrips, R. E., 2002. MapChart: software for the graphical presentation of linkage maps and QTLs. J. Hered., 1: 77-78

Vos, P., R. Hogers, M. Bleeker, M. Reijans, T. van De Lee, M. Hornes, A. Friters, J. Pot, J. Paleman and M. Kuiper, 1995. AFLP: a new technique for DNA fingerprinting. Nucleic. Acids. Res., 21: 44074414

Wang, D., Y. Li, L. Li, Y. Wei and Li Z, 2014. The first genetic linkage map of Eucommia ulmoides. J. Genet., 93: 13-20

Xue, D., S. Feng, H. Zhao, H. Jiang, B. Shen, N. Shi, J. Lu, J. Liu and H. Wang, 2010. The linkage maps of Dendrobium species based on RAPD and SRAP markers. J. Genet. Genom., 3: 197-204

Yan, Z., C. Denneboom, A. Hattendorf, O. Dolstra, T. Debener, P. Stam and P.B. Visser, 2005. Construction of an integrated map of rose with AFLP, SSR, PK, RGA, RFLP, SCAR and morphological markers. Theor. Appl. Genet., 4: 766-777

Zhang, F., S. Chen, F. Chen, W. Fang and F. Li, 2010. A preliminary genetic linkage map of chrysanthemum (Chrysanthemum morifolium) cultivars using RAPD, ISSR and AFLP markers. Sci. Hortic., 3: 422428

Zheng, Y., H. Guo, G. Zang and J. Liu, 2013. Genetic linkage maps of centipedegrass [Eremochloa ophiuroides (Munro) Hack] based on sequence-related amplified polymorphism and expressed sequence tag-simple sequence repeat markers. Sci. Hortic., 156: 86-92

(Received 22 December 2016; Accepted 17 February 2017) 